\title{
The Relationship between Working Memory and Metaphor Comprehension in Patients with Right Hemisphere Damage
}

\author{
Hyo Dong Shin ${ }^{a}$, Soyoung Choi ${ }^{\mathrm{b}}$ \\ ${ }^{a}$ Department of Speech-Language Pathology, Graduate School, Dankook University, Yongin, Korea \\ ${ }^{b}$ Graduate School of Special Education, Dankook University, Yongin, Korea
}

Correspondence: Soyoung Choi, $\mathrm{PhD}$ Graduate School of Special Education, Dankook University, 152 Jukjeon-ro, Suji-gu, Yongin 16890, Korea

Tel: +82-31-8005-3813

Fax: +82-31-8021-7144

E-mail: syc529@dankook.ac.kr

Received: October 2, 2017

Revised: November 20, 2017

Accepted: November 29, 2017

This article is based on a part of the first author's master's thesis from Dankook University.

\begin{abstract}
Objectives: Metaphor comprehension is an aspect of pragmatics. Since working memory is recognized as a skill needed for the understanding of metaphors, it is necessary to study the association between working memory and metaphor comprehension in patients with right hemisphere damage (RHD). Methods: Twelve patients with RHD (without aphasia) and twelve normal adults participated in this study. They were subjected to a metaphor comprehension task, which included a familiar conventional metaphor and a novel metaphor. Working memory was assessed using a numerical span task and a word span task. Results: The results indicated that the patients with RHD performed more poorly in the metaphor comprehension task compared to the normal adult group. However, both groups exhibited better comprehension of the conventional metaphor than the novel metaphor. Furthermore, the patients with RHD performed poorly in all working memory tasks compared to the normal adult group. The normal adult group showed significant and static correlation in conventional metaphor comprehension and word span tasks. In contrast, the RHD group showed significant correlations between all of the working memory tasks and each of the two metaphor types. Conclusion: The results of this study indicate that patients with RHD display defects in working memory as well as in metaphor comprehension compared to normal adults. This implies that limited working memory affects an individual's understanding of the meaning of words and sentences within a metaphor.
\end{abstract}

Keywords: Right hemisphere damage (RHD), Metaphor, Working memory
우반구 손상 환자들은 의사소통 시 화용론적 결함을 두드러지 게 보이며, 그 중에서도 은유, 속담, 관용구 등과 같은 비유언어를 이해하고 사용하는 측면에서의 어려움이 지속적으로 보고되고 있 다(Chung, 2008; Kim \& Choi, 2009; Brownell, Simpson, Bihrle, Potter, \& Gardner, 1990; Myers, 1999; Rinaldi, Marangolo, \& Baldassarri, 2004; Winner \& Gardner, 1977). 은유는 비유언어의 가장 대표적인 유형으로, 유사성이나 유추적인 관계(analogical relation) 에 있는 두 개의 다른 단어나 더 큰 문자적 요소들을 관련시켜서 표 현하는 것이며, ‘A는 B이다’라는 기본적인 형태를 가진다(Leonard, 1998; Nippold \& Fay, 1983). 즉, 은유는 비유하는 대상인 주제어 (A), 비유되는 대상인 매개어(B), 그리고 이 둘 사이의 공유된 특성
으로 이루어지는데, 이 공유된 특성을 추론하는 것이 은유표현의 이해에 핵심이 된다. 은유를 구성하는 문자적 의미와 실질적 의미 의 관계는 지시적이 아닌 함축적이고 유추적인 특성을 가지기 때 문에 은유표현을 이해하기 위해서는 은유적인 의미가 활성화되는 과정(상향식 처리과정)과 의사소통 환경에서 단서를 습득하는 과 정(하향식 처리과정)이 복합적으로 요구된다(Burgess \& Chialleo, 1996). 이러한 처리 과정에 우반구의 기능이 중요한 역할을 하기에 우반구 손상 환자의 경우 은유이해에 어려움을 보이게 된다는 것 이다(Beeman, 1998; Natalie \& Christine, 2007). 유사한 맥락에서 중의성, 유머, 추론 등 다중적 해석이 가능한 의미 처리 상황에서 적절한 해석을 걸러내는 데 우반구의 기능이 주로 작용한다는 관 
점으로 우반구 손상 환자가 겪는 은유 이해의 어려움을 설명하기 도 한다(Schmidt, De Buse, \& Seger, 2007; Schmidt \& Seger, 2009). 다만 이와 관련하여 다소 상반되는 연구결과들이 보고되고 있는 데, 다수의 연구에서 우반구 손상 환자들이 은유적 의미를 이해하 는 능력이 부족하고 은유 문장을 사전적 의미로 해석하는 오류를 보인다고 하였으나(Anaki, Faust, \& Kravetz, 1998; Rinaldi et al., 2004) 일부 연구들은 우반구 손상 환자들에게도 은유이해능력이 보존되어 있음을 관찰하였다(Gagnon, Goulet, Giroux, \& Joanette, 2003; Tompkins, 1990; Tompkins, Boada, \& McGarry, 1992). 경험 적 자료들에서 나타난 이 같은 차이는 연구에 참여한 개인의 영향 뿐 아니라 연구 과제 및 자극의 특성이 달랐기 때문일 수 있다. 선행 연구들은 자극의 수준(예: 단일단어, 문장) 및 제시 방법(예: 청각 적, 시각적), 과제 유형(예: 그림 선택, 구어 반응) 등이 상이하였으 며, 일부가 유사한 조건 하에서도 일치하지 않는 결과가 보고된 경 우가 있어 여전히 추가적인 연구가 필요한 상태이다.

한편, 은유이해 특성은 은유의 양식, 문맥, 구문 구조 등 다양한 요인의 영향을 받는다고 알려져 있으며 특히 친숙성(conventionality)이 주요하게 다루어져 왔다(Bowdle \& Gentner, 2005; Lundgren \& Brownell, 2016; Pollio \& Pollio, 1979). 연구자들은 일상적 인 언어에 흡수되어서 반복적으로 사용되는 은유를 관습적 은유 (conventionalized metaphor) 또는 고정된 은유(frozen metaphor) 라 하며, 새로운 정보를 제공하고 흔하지 않게 사용되는 은유를 새 로운 은유(novel metaphor)라고 정의하였다. 친숙성이 높은 전자 와 같은 은유는 표현 전체가 하나의 단위처럼 이해되지만 친숙성이 낮은 후자와 같은 은유는 일단 문자적 해석을 거친 뒤 그것이 적절 하지 않을 경우 대안적인 분석이 진행된다(Lai, van Dam, Conant, Binder, \& Desai, 2015). 다시 말해, 관습적 은유는 보편적 경험에 근 거하여 만들어지고 두 개념 사이의 관계가 보통 한 가지 의미로 고 정되어 관행적으로 사용되는 반면, 새로운 은유는 특수한 경험이 나 이미지에 기초하며 기존의 개념이 주관적으로 결합되는 특성을 가지기 때문에 서로 다른 처리과정을 거칠 수 있다. Mashal (2013) 은 새로운 은유를 이해하기 위해서 주제어가 속한 개념적 범주와 매개어가 지닌 대상적 속성을 적절하게 연결지을 수 있는지 비선택 적으로(non-selectively) 비교하여 확인하는 절차가 추가적으로 소 요된다고 보았다.

일반 성인을 대상으로 뇌영상기법을 사용한 연구들은 은유의 친숙도와 뇌기능의 관련성을 직접적으로 확인하고자 하였으며, 친 숙하고 상투적인 은유 관계에서 좌반구가 더 민감하게 반응하고 친숙하지 않은 은유 관계에서는 우반구가 더 민감하게 반응한다는 결과를 보고하였다(Bottini et al., 1994; Faust, 2012; Mashal, Faust,
Hendler, \& Jung-Beeman, 2007). 관습적 은유를 비롯하여 속담, 관 용어와 같은 친숙한 표현들은 마치 하나의 단위처럼 심상어휘집 (mental lexicon)에 그 고유 의미가 입력되어 있기 때문에 좌반구에 서 의미를 찾는데 반해, 새로운 은유표현은 그 의미가 입력되어 있 지 않아 우반구에서 우선적으로 처리된다는 것이다(Giora, 2007). 아직까지 국내외를 포괄하여 우반구 손상 환자를 대상으로 비유언 어 능력을 살펴본 연구는 그 자체로 드물뿐더러, 우반구 손상 환자 들의 은유이해 특성을 살펴보기 위해 일부 진행된 연구에서도 은 유표현의 친숙도를 직접적으로 조작한 경우는 찾아보기 어렵고 속 담, 관용구와 같은 친숙성이 높은 자극을 사용하였거나 은유표현 의 친숙도가 통제된 조건에서 언어유추 및 단어연상 능력과의 관련 성이나 과제 제시조건이 미치는 영향을 보고하였다(Chung, 2008; Kim, 2008; Kim \& Choi, 2009; Lee, Lim, \& Hwang, 2009; Rinaldi et al., 2004; Tompkins, 1990; Van Lancker \& Kempler, 1987; Winner \& Gardner, 1977). 이에 본 연구는 은유의 친숙성에 따른 차이 를 우반구 손상 환자들과 일반 성인들에서 비교해보고자 하였다.

은유를 이해하는 과정에 관여하는 대표적인 변인 중 하나로 작 업기억(working memory)을 들 수 있다. 작업기억이란 정보를 일시 적으로 저장하고 처리하기 위해 사용되는 능력으로 과제를 수행할 때 입력되는 자극을 저장함과 동시에 이해, 학습, 추론과 같은 고차 원적인 인지 처리를 가능하게 한다(Baddeley, 1993). 작업기억 공간 의 용량은 한정되어 있으며, 저장과 처리의 기능을 동시에 수행하기 에 어느 한 쪽에 자원을 소모하게 되면 전반적인 효율이 감소하게 되는 특성이 있다. 또한 작업기억은 다양한 인지 과정과 연관된 기 억체계로, 특히 언어 처리 과정에서 문장 또는 담화 속에 있는 연속 적인 내용들을 저장하고 통합하는 데 결정적인 역할을 하기 때문 에 작업기억 용량이 클수록 뛰어난 언어이해능력을 보인다(de Jong, 1998; Just \& Carpenter, 1992). 은유이해와작업기억 능력과의 관련 성을 살펴본 연구들 역시 작업기억 능력이 뛰어난 집단에서 보다 신속하고 정확한 은유이해가 가능하였음을 확인하였다(Blasko, 1999; Kazmerski, Blasko, \& Dessalegn, 2003; Pierce, MacLaren, \& Chiappe, 2010). 이 같은 결과는 은유표현의 이해를 위해 언어 자극 을 해체하고 비교 분석한 뒤 재해석하는 과정에서 저장과 처리를 동시에 수행하는 능력이 필요하기 때문에 인지적 자원을 효율적으 로 관리하고 분배하는 작업기억능력이 높을수록 은유적 의미를 더 빠르게 처리할 수 있음을 시사하였다. 특히 숫자 바로 따라말하 기 과제와 숫자 거꾸로 따라말하기 과제를 실시하였을 때 숫자 거 꾸로 따라말하기 능력과 은유이해능력이 더 밀접한 관계가 있는 것으로 나타났는데, 다수의 연구자들은 바로 따라말하기 과제에 비해 거꾸로 따라말하기 과제를 수행할 때 작업기억의 기능이 상대 
적으로 더 많이 관여하는 것으로 간주하고 있다(Chiappe \& Chiappe, 2007; Kintsch, 2000; Pierce \& Chiappe, 2008). 거꾸로 따라 말하기 과제를 수행하기 위해서는 작업기억 내에 순차적으로 제시 되는 자극을 일시적으로 저장하여 유지함과 동시에 들려진 순서를 억제하고 거꾸로 재배열해야 하는 추가적인 처리가 필요하다는 것 이다. 비록 단기기억과 작업기억은 이론적 바탕이나 행동적 지표면 에서 분리된 기제로 여겨지나 두 유형의 복합된 양상으로 작업기억 용량을 측정하기도 하며(Engle \& Kane, 2004), 단일 과제를 사용 하는 것보다 둘 이상의 과제로 단기 및 작업기억용량을 측정하였 을 때 평가의 신뢰도가 높다는 주장도 있다(Sung, 2011). 실제로 작 업기억능력을 살펴보는 과제의 구성은 연구마다 다양하여 일부 연 구자는 숫자 바로 따라말하기와 거꾸로 따라말하기의 합산 점수를 사용하였으며(Lee, Cho, Lee, 2010; Lee \& Kim, 2003), 둘 중 하나의 유형만 사용한 연구들도 보고되어 있다(Ko, Choi, Hwang, 2009; Oh \& Goo, 2008). 다른 한편에서는 은유이해에 미치는 작업기억의 영향이 억제적 통제와 관련된 실행 기능에서 비롯된다고 보는 견해 가 제안되었다(Gernsbacher, Keysar, Robertson, \& Werner, 2001; Pierce et al., 2010). 은유의미를 해석하는 과정에서 활성화되는 여 러 의미적 대안 중에 적절하지 않은 것을 억제하는 기능이 요구되는 데 작업기억용량이 부족한 이들은 이에 어려움을 겪는다는 것이다. 이처럼 은유이해에 작업기억의 어떤 하위 요소가 보다 깊이 관 여하는가에 대해서는 논의가 진행 중이지만 우반구 손상 환자들 이 일반 성인에 비해 작업기억용량에서 유의미한 감소를 보였다는 연구결과가 보고되어 있으며, 이는 우반구 손상 환자들이 언어적 정보를 저장하고 처리하는 과정에서 어려움을 겪는 원인 중 하나 로 해석되고 있다(Blasko, 1999; Kazmerski et al., 2003; Park \& Kim, 2012; Tompkins et al., 1992). 또한 일부 연구자는 우반구의 중앙 및 하측 전두영역(middle and inferior frontal regions)이 작업기억 내 에 저장할 정보를 선별, 억제하는 등의 조작과 관련된 실행 기능을 주로 담당한다고 주장하기도 하였다(Wager \& Smith, 2003). 그러 나 국내에서 은유이해 수행과 작업기억능력의 관계를 다룬 연구는 부족한 실정으로, 최근에서야 언어능력이 발달 중인 아동을 대상 으로 한 연구가 일부 진행된 바 있으나 취학전 일반 아동들에서 두 변인 간의 유의한 정적 상관이 보고된 반면(Yoo, 2014) 학령기 단순 언어장애 아동에게서는 유의미한 상관관계가 나타나지 않았다 (Hong \& Yim, 2014). 정리하자면 본 연구는 (1) 우반구 손상 환자들 과 일반 성인 간에 은유 유형(관습적 은유/새로운 은유)에 따른 은 유이해 수행의 차이가 있는지 알아보고, (2) 작업기억 과제를 유형 (숫자 폭/단어 폭) 및 속성(바로 따라말하기/거꾸로 따라말하기)별 로 실시하여 두 집단의 수행을 비교한 뒤, (3) 이를 바탕으로 은유이
해 수행과작업기억 능력의 관련성을 확인해보고자 하였다.

\section{연구방법}

\section{연구대상}

본 연구에는 우반구 손상 환자 12 명, 일반 성인 12 명이 참여하였 다. 우반구 손상 환자 집단의 참가자는 대학병원에서 우반구 손상 으로 진단받은 환자 중 뇌졸중(stroke)으로 인한 단일 반구 손상으 로 제한하였다. 이들은 (1) 파라다이스.한국판 웨스턴 실어증 검사 (Paradise -Korean version-the Western Aphasia Battery, P.K-WAB; $\mathrm{Kim} \& \mathrm{Na}, 2001$ ) 결과, 실어증 양상이 없었고(실어증지수[Aphasia Quotient] 90 이상), (2) 한국어가 모국어이면서 중졸 이상의 학력 으로 문장 읽기가 가능하고, (3) 한국형 간이정신상태과제(Korean Mini-Mental State Examination, K-MMSE; Kang, Na, \& Hahn, 1997)에서 24점 이상에 해당하였다. 또한 (4) 발병 전 뇌손상 및 기 타 신경학적 병력이 없으며, (5) 과제를 수행하기에 청력과 시력의 문 제가 없고, (6) 오른손잡이인 환자들이었다. 일반 성인 집단은 위의 (1)-(3) 기준을 모두 만족하여 언어 및 인지 기능이 정상 범위에 속 하는 이들로 구성하였다. 두 집단 참가자는 남성 5명 여성 7명으로 성별 비율이 동일하였으며, 독립표본 $t$-검정(independent sample $t$ test) 결과 연령 $(t=.199, p>.05)$ 과 교육연수 $(t=.169, p>.05)$ 에서 통 계적으로 유의미한 차이가 나타나지 않았다. 집단별 참가자 정보는 Table 1과 같고, 그 외 상세 사항은 Appendix 1에 제시하였다.

\section{연구도구}

은유이해 과제는 Chung (2003)에서 사용된 문장을 일부 발췌하 여 수정·보완하였다. 'A는 B이다'의 형태로 통일된 위 연구의 문장 은 일반대학생 30명을 대상으로 은유의 관습적인 정도를 7점 척도 $(1=$ 매우 새롭다, $7=$ 매우 관습적이다 $)$ 로 평정하도록 하여 타당도 를 검증한 바 있으며, 관습적 은유(평균 5.96)와 새로운 은유(평균 3.30), 각 30 문항으로 구성되어 있다. 선행연구를 참조하여 본 연구 에서도 일상적인 언어에 흡수되어 빈번하게 사용되는 은유를 관습

Table 1. Participants' characteristics

\begin{tabular}{lcl}
\hline & $\mathrm{RHD}(\mathrm{N}=12)$ & $\mathrm{NC}(\mathrm{N}=12)$ \\
\hline Age (yr) & $59.17(5.06)$ & $58.75(5.17)$ \\
Education (yr) & $12.67(2.43)$ & $12.50(2.39)$ \\
K-MMSE & $26.42(1.88)$ & $29.42(0.67)$ \\
\hline
\end{tabular}

Values are presented as mean (SD).

$\mathrm{RHD}=$ right hemisphere damage group; $\mathrm{NC}=$ normal control group; $\mathrm{K}-\mathrm{MMSE}=$ Korea version of Mini-Mental Status Examination (Kang, Na, \& Hahn, 1997). 
적 은유 유형으로, 목표영역에 대한 새로운 정보를 제공하고 흔하 지 않게 사용되는 은유를 새로운 은유 유형으로 구분하였다(Pollio \& Pollio, 1979).

본 과제의 형태는 은유문장을 읽고 제시된 보기 중에서 적절한 것을 고르는 것으로, 총 3 개의 보기가 주어진 택일형 보기를 추가 로 제작하였다. 택일형 과제는 상위인지적 언어지식이 요구되지 않 아 뇌손상 환자에게 과제를 실시하기 용이하고, 참가자의 반응에 대한 객관적인 채점이 가능하다는 이점이 있다(Chung, 2008). 3 개 의 보기 항목은 주어진 문장의 적절한 은유적 의미 해석에 해당하 는 정답 문항, 사전적 의미 해석에 해당하는 오답 1 문항, 은유 문장 과 관련이 없는 오답 1 문항으로 구성하였다. 예를 들어, '취업은 전 쟁이다'라는 문항에 대하여 적절한 은유적 해석의 정답은 '취업은 경쟁이 심하다'를 선택하는 것이며, 사전적 의미로 해석된 '취업은 폭력을 사용한다'와 관련 없는 해석인 '취업은 대기업이 좋다'는 오 답 보기에 해당한다. 보기 항목은 예시와 같이 모두 동일한 어휘로 시작하며, 그 길이가 3 어절 이상 차이 나지 않도록 하였다.

수정된 문장 및 제작된 보기의 적절성은 1 차로 언어병리학전공 교수의 검토를 거쳤다. 이후 일반 성인 10 명과 언어병리학전공 대학 원생 10 명에게 무작위로 문항을 제시하고, Likert식 5점 척도(1점= 전혀 들어보지 못하였다, 5점=매우 자주 사용한다) 평정을 받아 내용타당도 검증을 실시하였다. Nippold와 Fay (1983)에 기초하여 평균 2.0 을 기준으로 그 이상의 점수를 받은 문항은 관습적 은유 조건으로, 2.0 미만의 점수를 받은 문항의 경우 새로운 은유 조건 으로 확정하였다. 보기의 적절성 또한 5점 척도(1점=전혀 적절하 지 않음, 5 점 $=$ 매우 적절함) 평정을 받아 2점 이하를 획득한 항목 은 수정하였다. 최종 과제는 연습문항 2 개, 관습적 은유 조건 및 새 로운 은유 조건 각 15 개씩 총 32 문항으로 이루어졌다. 은유이해 과 제의 예시는 Appendix 2 에 제시하였다.

작업기억 과제는 한국판 웩슬러 성인용 지능검사 4판(Korean Wechsler Adult Intelligence Scale-IV, K-WAIS-IV; Hwang, Kim, Park, Choi, \& Hong, 2012)의 숫자 폭 과제와 Sung (2011)의 단어 폭 과제를 사용하였다. 숫자 폭 과제는 숫자 바로 따라말하기 과제 와 숫자 거꾸로 따라말하기 과제로 구성되어 있으며, 단어 폭 과제 의 경우 원 저자의 연구에서는 말-언어장애 환자를 대상으로 한 까 닭에 손가락 지시하기(pointing) 형태로 실시하였으나 본 연구의 참가자는 구어 산출에 어려움이 없음을 고려하여 구어로 회상하 기 형태로 바꾸어 진행하였다. 과제 구성을 살펴보면, 숫자 바로 따 라말하기는 각 폭마다 2문항씩 제시되며 2폭에서 9폭까지 총 16 문 항으로 구성되어 있고, 숫자 거꾸로 따라말하기는 각 폭마다 2 문항 씩 제시되지만 2 폭이 4 문항이고 이후 8 폭까지 총 16 문항으로 구성
되어 있다. 단어 바로 따라말하기는 각 폭마다 2 문항씩 제시되며 3 폭에서 9 폭까지 총 14 문항으로 구성되어 있고, 단어 거꾸로 따라말 하기는 각 폭마다 2문항씩 제시되며 2폭에서 8 폭까지 총 14 문항으 로 구성되어 있다.

\section{연구절차}

본 연구는 2017년 3-4월에 걸쳐 서울시 소재의 병원 내 언어치료 실에서 개별적으로 실시되었다. 본 실험의 진행에 앞서 우반구 손 상 환자 4 명, 일반 성인 4 명에게 예비실험을 실시하였을 때, 과제 수 행 및 연구 절차상 특별한 문제점은 발견되지 않았으나 두 과제를 모두 수행하는데 다소 장시간이 소요됨에 따라 본 실험은 총 2 회기 로 나누어 진행하였다. 첫 회기에는 연구에 대한 설명을 진행하며 참가자와의 친밀감을 형성하고 P.K-WAB 검사를 실시하였다. 일 주일 후 두 번째 회기에서는 은유이해 과제와 작업기억 과제를 진 행하였으며 학습 및 순서 효과를 배제하기 위해 두 과제의 진행 순 서는 역균등화(counterbalancing) 하였다. 은유이해 과제와작업기 억 과제를 모두 수행하는데 약 30 분 정도가 소요되었으며, 각 과제 별 진행 절차는 다음과 같았다.

은유이해 과제는 관습적 은유 15 문항과 새로운 은유 15 문항을 무선 배열한 뒤 $\mathrm{A} 4$ 용지에 인쇄하여 제공하였다. 참가자에게 제시 된 문장을 잘 읽고 보기 중 적절한 응답을 고르도록 지시하였으며 2 개의 연습 시행을 통해 수행 절차를 숙지하였다고 판단되면 본 시 행을 실시하였다. 연습 시행에서 오답을 선택하였을 경우 오답에 대 해 설명하고 은유적 해석을 들려준 후 보기 중에서 다시 정답을 선 택하도록 유도하였다. 본 시행에서는 간헐적으로 “잘 하셨어요”라 는 격려만 제공하였으며, 한 문항에서 1 분 이상의 시간이 걸릴 경우 재차 답을 요구하고 이후에도 보기를 선택하지 못하면 다음 시행 으로 진행하였다.

작업기억 과제 중 숫자 바로 따라말하기는 연구자가 들려주는 숫 자를 다 듣고 즉시 그대로 따라 말하는 과제로, 지시 사항을 안내하 면서 2 회의 연습 시행을 실시한 후 본 시행으로 진행하였으며, 적절 하게 응답하지 못하였을 경우 정반응을 제시해주었다. 모든 숫자 는 연구자가 구두로 제시하되, 자극 제시 속도를 일정하게 유지하 기 위해 초당 1 개씩 들려주었고 마지막 숫자의 경우 음의 높이를 살 짝 낮추어 제시하였다. 숫자 거꾸로 따라말하기는 연구자가 들려준 숫자를 뒤에서부터 거꾸로 따라 말하는 과제이며 절차는 위와 같 았다. 단어 바로 따라말하기는 연구자가 들려준 단어를 즉시 그대 로 따라 말하는 과제이며, 단어 거꾸로 따라말하기는 연구자가 들 려준 단어를 뒤에서부터 거꾸로 따라 말하는 과제이다. 진행 절차 는 숫자 따라말하기 유형과 동일하였다. 


\section{자료분석}

은유이해 과제는 관습적 은유 조건과 새로운 은유 조건 각 15 개 씩 총 30개 문항으로 구성되었으며, 각 문항에 대해서 정반응은 1 점, 오반응은 0 점으로 채점하였다. 작업기억 과제는 각 폭 당 두 문 항을 모두 맞출 시 2 점, 한 문항만 맞출 시 1점, 두 문항을 모두 틀릴 시 0 점으로 채점하였다.

수집된 자료는 통계분석 프로그램 SPSS version 18로 분석하였 다. 은유이해 과제를 수행하였을 때 일반 성인 집단과 우반구 손상 환자 집단 간에 은유 유형별(관습적 은유/새로운 은유) 차이가 유 의미한지 알아보기 위해 반복측정된 이원분산분석(repeated measure two-way ANOVA)을 실시하였다. 또한 작업기억 과제에서 하 위 유형별(숫자 바로 따라말하기, 숫자 거꾸로 따라말하기, 단어 바 로 따라말하기, 단어 거꾸로 따라말하기) 수행능력에 집단 간 유의 미한 차이가 있는지 확인하기 위해 각각 독립표본 $t$-검정(independent sample $t$-test)을 실시하였다. 마지막으로 두 집단에서 은유이 해 수행과 작업기억능력 간에 상관관계가 나타나는지 Pearson 적 률상관계수를 구하였다.

\section{연구결과}

본 연구는 우반구 손상 환자들이 어려움을 보이는 것으로 알려 진 화용 기능 중 은유이해 특성을 친숙성에 따른 유형별로 살펴보 고, 작업기억과의 관련성을 확인하고자 하였다. 먼저, 우반구 손상 환자 집단과 일반 성인 집단이 은유이해 과제 수행 시 유형별(관습 적 은유/새로운 은유) 차이를 보이는지 분석하였다. 두 집단의 은 유이해 과제 정반응 점수 평균과 표준편차는 Table 2 와 같다. 집단

Table 2. Number of correct responses according to group and condition

\begin{tabular}{lcc}
\hline & RHD & NC \\
\hline Conventional metaphor & $9.17(3.10)$ & $14.17(.72)$ \\
Novel metaphor & $7.83(2.92)$ & $13.58(.52)$ \\
\hline
\end{tabular}

Values are presented as mean (SD).

$\mathrm{RHD}=$ right hemisphere damage group; $\mathrm{NC}=$ normal control group.

Table 3. Working memory task scores according to group and subtype

\begin{tabular}{lccc}
\hline & RHD & NC & $t$ \\
\hline Digit forward & $7.50(2.24)$ & $11.42(2.35)$ & $-4.180^{*}$ \\
Digit backward & $5.83(1.40)$ & $9.50(1.88)$ & $-5.409^{*}$ \\
Word forward & $3.42(1.51)$ & $6.75(1.49)$ & $-5.462^{*}$ \\
Word backward & $3.42(1.51)$ & $6.25(1.22)$ & $-5.074^{*}$ \\
\hline
\end{tabular}

Values are presented as mean (SD).

$\mathrm{RHD}=$ right hemisphere damage group; $\mathrm{NC}=$ normal control group. ${ }^{*} p<.001$.
(2)과 은유 유형(2)을 변인으로 하여 반복측정 이원분산분석을 실 시한 결과, 집단의 주효과 $\left(F_{(1,22)}=39.088, p<.001\right)$ 와 은유 유형의 주효과 $\left(F_{(1,22)}=18.954, p<.001\right)$ 모두 통계적으로 유의한 것으로 나 타났다. 즉, 일반 성인 집단이 우반구 손상 환자 집단에 비해 은유 이해 과제의 점수가 높았고, 관습적 은유 조건에서 새로운 은유 조 건에 비해 상대적으로 높은 수행을 보였다. 그러나 집단과 은유 유 형 간상호작용 효과는 나타나지 않았다 $\left(F_{(1,22)}=2.902, p>.05\right)$.

다음으로 우반구 손상 환자 집단과 정상 성인 집단이 작업기억 과제의 수행에서 차이가 있는지 살펴보았다. Table 3 에 제시된 바와 같이 모든 유형의 작업기억 과제에서 우반구 손상 환자 집단의 수 행 점수가 일반 성인 집단의 수행 점수보다 낮은 것으로 나타났고, 이 같은 차이는 통계적으로 유의미하였다( $p s<.001)$.

마지막으로 일반 성인 집단과 우반구 손상 환자 집단에서 은유 이해 수행과 작업기억능력 간의 상관관계를 살펴보기 위하여 Pearson 적률상관분석을 실시하였다. Table 4에서 보여지듯이 일반 성 인 집단의 경우 관습적 은유이해 점수와 단어 바로 따라말하기 $(r=.725, p<.01)$, 단어 거꾸로 따라말하기 $(r=.677, p<.05)$ 간에 유 의한 정적 상관관계가 나타났다. 즉, 작업기억 과제 중 단어 폭 과제 의 점수가 높은 이들은 관습적 은유이해 점수가 높은 경향을 보였 다. 그러나 관습적 은유이해 점수와 새로운 은유 은유이해 점수, 새 로운 은유이해 점수와 작업기억 과제들 간에는 유의한 상관이 나 타나지 않았다.

Table 4. Results of correlation analysis in the normal control group

\begin{tabular}{lcc}
\hline & Conventional metaphor & Novel metaphor \\
\hline Conventional metaphor & - & \\
Novel metaphor & .205 & - \\
Digit forward & .493 & .381 \\
Digit backward & .404 & .141 \\
Word forward & $.725^{* *}$ & .089 \\
Word backward & $.677^{*}$ & .182 \\
\hline
\end{tabular}

${ }^{*} p<.05,{ }^{* *} p<.01$.

Table 5. Results of correlation analysis in the RHD group

\begin{tabular}{lcc}
\hline & Conventional metaphor & Novel metaphor \\
\hline Conventional metaphor & - & \\
Novel metaphor & $.908^{* *}$ & - \\
Digit forward & $.892^{* *}$ & $.780^{* *}$ \\
Digit backward & $.655^{*}$ & $.592^{*}$ \\
Word forward & $.802^{* *}$ & $.700^{*}$ \\
Word backward & $.861^{* *}$ & $.783^{*}$ \\
\hline
\end{tabular}

$\mathrm{RHD}=$ right hemisphere damage group. ${ }^{*} p<.05,{ }^{* *} p<.01$. 
한편, 우반구 손상 환자 집단은 일반 성인 집단과는 달리 관습적 은유이해 점수와 새로운 은유이해 점수 간에도 높은 정적 상관이 관찰되었고 $(r=.908, p<.01)$, 관습적 은유이해 점수와 새로운 은유 이해 점수 각각은 작업기억 과제의 모든 하위유형 분류와 유의한 상관을 보였다(Table 5). 즉, 관습적 은유이해 점수와 숫자 바로 따라 말하기 $(r=.892, p<.01)$, 숫자 거꾸로 따라말하기 $(r=.655, p<.05)$, 단어 바로 따라말하기 $(r=.802, p<.01)$, 단어 거꾸로 따라말하기 $(r=.861, p<.01)$ 점수간에 유의한 정적 상관관계가 나타났다. 또한 새로운 은유이해 점수와 숫자 바로 따라말하기 $(r=.780, p<.01)$, 숫 자 거꾸로 따라말하기 $(r=.592, p<.05)$, 단어 바로 따라말하기 $(r=$ $.7002, p<.01)$, 단어 거꾸로 따라말하기 $(r=.783, p<.01)$ 점수 간에 유의한 정적 상관관계를 보였다. 다시 말해 우반구 손상 환자 집단 은 작업기억 과제에서 높은 수행을 보일수록 은유이해 점수가 높 은 경향을 나타냈다.

\section{논의 및 결론}

본 연구는 우반구 손상 환자 집단과 일반 성인 집단을 대상으로 은유 유형에 따른 은유이해능력의 차이와작업기억 특성을 살펴보 고 두 변인 간의 관계를 알아보았다. 은유 유형은 관습적 은유 조건 과 새로운 은유 조건으로 구분하였고, 작업기억은 숫자 폭과 단어 폭을 바로 따라말하기와 거꾸로 따라말하기 각각으로 측정하였다. 주요 연구결과는 아래와같다.

은유이해 과제를 수행하였을 때 우반구 손상 환자 집단은 일반 성인 집단에 비해 낮은 수행을 보였으나, 관습적 은유 조건을 새로 운 은유 조건보다 쉽게 이해하는 양상은 두 집단에서 유사하게 나 타났고 집단 요인과 은유 유형 조건의 상호작용 효과는 유의미하지 않았다. 우반구 손상 환자들이 은유이해에 어려움을 보인다는 선 행연구는 비교적 일관적으로 보고되어 왔다(Brownell et al., 1990; Gagnon et al., 2003; Rinaldi et al., 2004; Winner \& Gardner, 1977). 연구자들은 그 원인을 우반구 손상 환자들이 어휘목록 안에 있는 언어적인 정보를 활성화하는 능력이 부족하며, 함축적이고 간접적 인 의미보다 지시적이고 사전적인 의미를 선호하기 때문이라고 보 았다. 이 때문에 우반구 손상 환자는 추상적이고 함축적인 의미를 지닌 은유표현을 이해하는 데 어려움을 보일 수 있고, 문장 구성 성 분의 표면적인 의미에 의존하여 판단하는 경향이 있다는 것이다. 또한 중의성, 유머, 추론 등 다중적 해석이 가능한 의미 처리 상황 에서 적절한 해석을 걸러내는 데 우반구의 기능이 주로 작용한다 는 관점으로 우반구 손상 환자가 겪는 은유이해의 어려움을 설명 하기도 하였다(Schmidt et al., 2007; Schmidt \& Seger, 2009). 실제
로 본 연구에 참가한 우반구 손상 환자들은 은유 문장과 관련이 없 는 오답에 비해 사전적 의미 해석에 해당하는 오답을 선택하는 비 율이 높게 나타났다. 본 연구에 참여한 우반구 손상 환자 집단이 인 지 기능의 저하나 실어증 양상을 보이지 않는 참가자들로 구성되었 음에도 불구하고 일반 성인 집단에 비해 유의하게 낮은 은유이해 능력을 보인 점은 위와같은 맥락에서 해석될 수 있다.

은유 유형에 따른 수행 결과에서는 관습적 은유 점수가 새로운 은유 점수보다 유의미하게 더 높았다. 이는 새로운 은유에 비해 일 상적인 언어에 흡수되어 있는 관습적 은유의 이해가 더 쉽다는 선 행연구들과 일치하였으나(Burgess \& Chiarello, 1996; Pollio \& Pollio, 1979; Van Lancker \& Kempler, 1987), 친숙하지 않은 은유 관계 에서 우반구가 더 민감하게 반응하며 원활한 처리에 영향을 미친 다는 주장을 지지하는 양상으로 보기는 어려웠다(Beeman, 1998; Bottini et al., 1994; Faust, 2012; Mashal et al., 2007). 관습적 은유표 현의 경우 두 개념 사이의 관계가 보편적인 하나의 의미로 고정되어 관행적으로 사용됨에 따라 지시적 의미를 이해하는 과정에 가깝 게 처리되는 것에 비해, 새로운 은유표현을 이해하기 위해서는 주 제어가 속한 개념적 범주와 매개어가 지닌 대상적 속성을 적절하게 연결 지을 수 있는지 확인하는 절차를 반복한 뒤 의미를 재구성해 야 하기 때문에 추가적인 인지 언어 기능이 필요하게 된다(Mashal, 2013; Van Lancker \& Kempler, 1987). 한편, 관습적 은유와 새로운 은유 점수 간의 차이가 일반 성인 집단에 비해 우반구 손상 환자 집 단에서 크게 나타났으나 집단과 은유 유형 요인 간에 상호작용이 통계적으로 유의미하지 않았기 때문에 본 연구 결과만으로 은유의 친숙성과 우반구의 역할을 설명하기에는 다소 제약이 있다. 다만 일반 성인 집단의 은유 이해 점수가 두 조건 모두에서 천장(ceiling) 에 가까웠던 점으로 미루어 후속 연구에서는 은유 과제의 난이도 를 보다 면밀히 검토할 필요가 있다.

다음으로 두 집단의 작업기억능력을 분석한 결과, 우반구 손상 환자 집단은 정상 성인 집단에 비해 모든 유형의 작업기억 과제에 서 유의하게 낮은 수행을 보임이 확인되었다. 또한 참가자마다 개인 차가 있기는 하지만 거꾸로 따라말하기 과제가 바로 따라말하기 과 제에 비해 더 어려운 경향을 보였으며, 두 집단에서 공통적으로 숫 자폭 과제보다 단어폭 과제의 점수가 상대적으로 낮았다. 우반구 손상 환자들이 일반 성인에 비해 저하된 언어이해능력을 가지고 있 음을 보고한 선행연구 중 일부는 그 원인을 작업기억 용량의 제한 으로 설명한 바 있다(Blasko, 1999; Kazmerski et al., 2003; Tompkins et al., 1992). 작업기억의 하위 요소 중 중앙 집행기는 정보를 저장하고 처리하기에 한정된 용량을 보유하고 있으며, 과제 수행에 요구되는 부담이 제한된 범위를 초과하게 되면 저장과 처리 기능 
중 일부 또는 상호적인 손실을 유발함으로써 시간 지연이나 오류를 발생시킨다(Kintsch, 2000; Mashal, 2013). 결과적으로 증가된 과제 의 부담과 작업기억 공간의 제약으로 인해 우반구 손상 환자들이 상대적으로 과제 수행에 더욱 어려움을 보였을 것이라고 추정할 수 있다.

마지막으로 은유이해능력과 작업기억의 상관관계를 살펴보았 다. 두 변인의 관련성에 대하여 선행연구들이 주장하는 바는, 은유 표현의 이해를 위해 언어 자극을 해체하고 비교 분석한 뒤 재해석 하는 과정에 저장과 처리가 동시에 요구되는데, 인지적 자원을 효 율적으로 관리하고 분배하는 작업기억능력이 높을수록 은유적 의 미를 더 빠르게 처리할 수 있다는 것이다(Blasko, 1999; Hong \& Yim, 2014; Yoo, 2014). 특히 어휘습득은 물론 정확한 구문 구조의 이해와 사용 등 언어의 전반적인 영역에 실행 기능이 영향을 미치 기 때문에 작업기억능력이 높을수록 은유적 의미 역시 효과적으 로 처리할 수 있다고 보았다(Marton \& Schwartz, 2003). 특히 일부 연구자들은 작업기억이 상대적으로 더 많이 관여하는 거꾸로 따 라말하기 과제와 은유이해능력과의 상관관계를 밝힘으로써 작업 기억의 영향이 억제적 통제와 관련된 실행 기능에서 비롯된다고 주장하였다(Chiappe \& Chiappe, 2007; Kintsch, 2000; Mashal, 2013; Pierce \& Chiappe, 2008). 본 연구의 결과는 그와 다소 상반된 양상을 보였다. 먼저 일반 성인 집단은 단어폭 과제와 관습적 은유 조건 간에만 유의한 상관을 보였는데, 앞서 언급한 바와 같이 본 연 구에 포함된 과제의 부담이 일반 성인들에게는 작업 기억의 손실 을 유발할 만큼 크지 않았던 것으로 여겨지며 작업기억 과제 내에 서도 단어폭 과제와 숫자폭 과제의 난이도 차이가 존재하므로 그 에 따라 두 변인의 유의미한 상관 관계를 관찰하기 어려웠을 가능 성이 있다. 한편, 우반구 손상 환자들의 경우는 두 은유 유형 각각 이 모든 유형의 작업기억 과제와 비교적 높은 상관을 나타냈다. Mashal (2013)에서도 관습적 은유 조건에서 새로운 은유 조건에 비해 이해 점수가 높았으나 친숙성에 따른 상관관계의 차이를 확인 하지는 못하였다. 이에 대해 연구자는 은유 관계를 이해하기 위해 활성화된 대안적 의미 중 관련 없는 정보들을 억제하는 과정은 두 조건에서 유사하며 친숙한 은유 유형의 경우 이 같은 과정에 소비 되는 인지적 자원이 상대적으로 적다고 설명하였다. 단, 본 연구에 서는 바로 따라말하기 과제 또한 은유 이해 수행과 관련이 있는 것 으로 나타났는데, 실어증 환자를 대상으로 단기기억 및 작업기억용 량과 문장처리와의 상관을 살펴본 Sung (2010)에서도 단기기억과 제인 바로 따라 지시하기 과제에서만 문장이해 수행과 유의한 상관 관계가 보고된 바 있다. 보통 상위 인지기제(higherorder cognitive mechanism)를 측정하는 유형의 작업기억과제 수행이 문장이해와
높은 상관관계를 보이는 것으로 알려진 것과 상반되는 결과에 대 하여 연구자는 과제의 난이도에 따라 기억폭 점수의 분포가 상이 한 까닭에 상관관계의 통계적 검증이 어려웠을 수 있음을 원인으 로 제안하였다. 본 연구의 우반구 손상 환자 집단에서도 유사하게 난이도가 비교적 쉬운 숫자 바로 따라말하기는 3-11점의 점수 편차 를 보인 반면 난이도가 높은 단어 거꾸로 따라말하기는 2-7점의 상 대적으로 적은 변화폭를 보였으며, 이러한 점수 분포의 제한은 집 단의 다양성(variability)을 감소시킴으로써 통계 분석 결과에 영향 을 미쳤을수 있다.

작업기억 과제에서 나타난 집단 간 차이는 우반구 손상 환자들 의 언어적 결함이 작업기억과 관련 있음을 짐작케 하지만 본 연구 의 결과만으로 비유 언어 처리 과정과 관련된 우반구의 역할을 파 악하기에는 제한이 있으며, 은유이해 수행과 작업기억능력의 관계 를 살펴본 소수 연구들에서 일치하지 않는 결과가 보고된 만큼 추 후 지속적인 탐구가 요구된다. 또한 본 연구의 참여자들이 인지 및 언어 측면에서 장애 양상이 두드러지지 않았다는 점을 고려할 때 연구 결과를 일반화하여 해석하는 데에 주의를 요한다. 그럼에도 불구하고 본 연구는 우반구 손상 환자들을 대상으로 은유 유형에 따른 이해 특성과 작업기억능력을 체계적으로 측정하여 일반 성인 집단과 비교하였고, 나아가 두 변인의 상관관계를 밝히고자 시도하 였다는데 그 의의가 있다. 본 연구결과를 토대로 우반구 손상 환자 들이 보이는 화용적 언어 문제의 근본적인 기제(underlying mechanism)에 대한 이해를 증진하는 연구가 이어지기를 기대하며, 이 같은 노력은 임상적 평가와 중재에 근거기반(evidence based) 접근 을 시도함에 있어 경험적 자료로 활용될 수 있으리라 생각한다.

\section{REFERENCES}

Anaki, D., Faust, M., \& Kravetz, S. (1998). Cerebral hemispheric asymmetries in processing lexical metaphors. Neuropsychologia, 36, 353-362.

Baddeley, A. (1993). Working memory and conscious awareness. In A. F, Collins et al. (Eds.), Theories of memory (pp. 11-20). Hove, UK: Lawrence Erlbaum Associates.

Beeman, M. (1998). Coarse semantic coding and discourse comprehension. In M. Beeman \& C. Chiarello (Eds.), Right hemisphere language comprehension: perspectives from cognitive neuroscience (pp. 255-284). Mahwah, NJ: Erlbaum.

Blasko, D. G. (1999). Only the tip of the iceberg: who understands what about metaphor? Journal of Pragmatics, 31, 1675-1683.

Bottini, G., Corcoran, R., Sterzi, R., Paulesu, E., Schenone, P., Scarpa, P., ... \& 
Frith, D. (1994). The role of the right hemisphere in the interpretation of figurative aspects of language: a positron emission tomography activation study. Brain, 117, 1241-1253.

Bowdle, B. F., \& Gentner, D. (2005). The career of metaphor. Psychological Review, 112, 193-216.

Brownell, H. H., Simpson, T. L., Bihrle, A. M., Potter, H. H., \& Gardner, H. (1990). Appreciation of metaphoric alternative word meanings by left and right brain-damaged patients. Neuropsychologia, 28, 375-383.

Burgess, C., \& Chiarello, C. (1996). Neurocognitive mechanisms underlying metaphor comprehension and other figurative language. Metaphor and Symbol, 11, 67-84.

Chiappe, D. L., \& Chiappe, P. (2007). The role of working memory in metaphor production and comprehension. Journal of Memory and Language, $56,172-188$.

Chung, S. E. (2008). The idiom comprehension of the patients with brain damage (Master's thesis). Ewha Womans University, Seoul, Korea.

Chung, W. K. (2003). Initial process of metaphor interpretation: structure-mapping theory vs class-inclusion theory (Master's thesis). Ewha Womans University, Seoul, Korea.

de Jong, P. F. (1998). Working memory deficits of reading disabled children. Journal of Experimental Child Psychology, 70, 75-96.

Engle, R. W., \& Kane, M. J. (2004). Executive attention, working memory capacity, and a two-factor theory of cognitive control. In B. Ross (Ed.), The psychology of learning and motivation (pp. 145-199). New York, NY: Academic Press.

Faust, M. (2012). Thinking outside the left box: the role of the right hemisphere in novel metaphor comprehension. In M. Faust (Ed.), The handbook of the neuropsychology of language (pp. 425-448). Chichester: Wiley-Blackwell.

Gagnon, L., Goulet, P., Giroux, F., \& Joanette, Y. (2003). Processing of metaphoric and non-metaphoric alternative meanings of words after right-and left-hemispheric lesion. Brain and Language, 87, 217-226.

Gernsbacher, M. A., Keysar, B., Robertson, R. R., \& Werner, N. K. (2001). The role of suppression and enhancement in understanding metaphors. Journal of Memory and Language, 45, 433-450.

Giora, R. (2007). Is metaphor special? Brain and Language, 100, 111-114.

Hong, Y., \& Yim, D. (2014). The relationship between working memory and metaphor comprehension in school-age children with specific language impairments. Communication Sciences \& Disorders, 19, 191-198.

Hwang, S. T., Kim, J. H., Park, K. B., Choi, J. Y., \& Hong, S. H. (2012). KoreanWechsler Adult Intelligence Scale IV (K-WAIS-IV). Daegu: Korea Psycholo- gy Co.

Just, M. A., \& Carpenter, P. A. (1992). A capacity theory of comprehension: individual differences in working memory. Psychological Review, 99, 122149.

Kang, Y., Na, D. L., \& Hahn, S. (1997). A validity study on the Korean MiniMental State Examination (K-MMSE) in dementia patients. Journal of the Korean Neurological Association, 15, 300-308.

Kazmerski, V. A., Blasko, D. G., \& Dessalegn, B. G. (2003). ERP and behavioral evidence of individual differences in metaphor comprehension. Memory and Cognition, 31, 673-689.

Kim, E. J., \& Choi, Y. (2009). Metaphor comprehension with a damaged right hemisphere: focusing on word association and verbal analogical processes. Korean Journal of Communication \& Disorders, 14, 70-81.

Kim, H. H., \& Na, D. L. (2001). Paradise.Korean version-Western Aphasia Battery $(K-W A B)$. Seoul: Paradise Welfare Foundation.

Kim, M. Y. (2008). The comprehension of proverb in patients with right-hemisphere damaged: the role of familiarity and context (Master's thesis). Ewha Womans University, Seoul, Korea.

Kintsch, W. (2000). Metaphor comprehension: a computational theory. Psychonomic Bulletin \& Review, 7, 257-266.

Ko, S. H., Choi, K. S., \& Hwang, M. (2009). The development of reading span in children. Korean Journal of Communication \& Disorders, 14, 303-312.

Lai, V. T., van Dam, W., Conant, L. L., Binder, J. R., \& Desai, R. H. (2015). Familiarity differentially affects right hemisphere contributions to processing metaphors and literals. Frontiers in Human Neuroscience, 9, 1-10.

Lee, C. M., \& Kim, Y. W. (2003). Working memory of deaf signers. Korean Journal of Communication \& Disorders, 8, 209-227.

Lee, S. E., Cho, M. R., \& Lee, Y. K. (2010). The relationship between listening comprehension and working memory in school-aged children. Korean Journal of Communication \& Disorders, 15, 56-65.

Lee, S. H., Lim, J., \& Hwang, M. (2009). Metaphor comprehension in adults with right-hemisphere brain damage: some effects of task presentation conditions. Korean Journal of Communication \& Disorders, 14, 484-494.

Leonard, L. B. (1998). Children with specific language impairment. Cambridge, MA: MIT Press.

Lundgren, K., \& Brownell, H. (2016). Figurative language deficits associated with right hemisphere disorder. Perspectives of the ASHA Special Interest Groups, 1, 66-81.

Marton, K., \& Schwartz, R. G. (2003). Working memory capacity and language processes in children with specific language impairment. Journal of 
Speech, Language, and Hearing Research, 46, 1138-1153.

Mashal, N. (2013). The role of working memory in the comprehension of unfamiliar and familiar metaphors. Language and Cognition, 5, 409-436.

Mashal, N., Faust, M., Hendler, T., \& Jung-Beeman, M. (2007). An fMRI investigation of the neural correlates underlying the processing of novel metaphoric expressions. Brain and Language, 100, 115-126.

Myers, P. S. (1999). Right hemisphere damage: disorders of communication and cognition. New York, NY: Singular Publishing Group.

Natalie, A. K., \& Christine, C. (2007). Understanding metaphors: is the right hemisphere uniquely involved? Brain and Language, 100, 188-207.

Nippold, M. A., \& Fey, S. H. (1983). Metaphoric understanding in preadolescents having a history of language acquisition difficulties. Language, Speech, and Hearing Services in Schools, 14, 171-180.

Oh, K. M., \& Goo, S. Y. (2008). Inhibitory control, working memory, and language ability in 4-5 year-old normal children and children with developmental language delay. Korean Journal of Communication Disorder, 13, 263-281.

Park, W. K., \& Kim, K. (2012). Declined working memory in patients with right cerebral hemispheric lesions. Korean Journal of Clinical Geriatrics, 13, 186-193.

Pierce, R. S., \& Chiappe, D. L. (2008). The roles of aptness, conventionality, and working memory in the production of metaphors and similes. Metaphor and Symbol, 24, 1-19.

Pierce, R. S., MacLaren, R., \& Chiappe, D. L. (2010). The role of working memory in the metaphor interference effect. Psychonomic Bulletin \& Review, 17, 400-404.

Pollio, M. R., \& Pollio, H. R. (1979). A test of metaphoric comprehension and some preliminary developmental data. Journal of Child Language, 6, 111120.

Rinaldi, M. C., Marangolo, P., \& Baldassarri, F. (2004). Metaphor comprehension in right brain-damaged patients with visuo-verbal and verbal material: a dissociation (re)considered. Cortex, 40, 479-490.
Schmidt, G. L., \& Seger, C. A. (2009). Neural correlates of metaphor processing: the roles of figurativeness, familiarity and difficulty. Brain and Cognition, 71, 375-386.

Schmidt, G. L., De Buse, C. J., \& Seger, C. A. (2007). Right hemisphere metaphor processing? Characterizing the lateralization of semantic processes. Brain and Language, 100, 127-141.

Sung, J. E. (2010). Performances on short-term and working memory tasks and their relationships to aphasia severity and auditory comprehension in normal elderly adults and people with aphasia. Korean Journal of Communication \& Disorders, 15, 285-297.

Sung, J. E. (2011). The reliability and validity of short-term and working memory pointing tasks developed for clinical populations with speech and language disorders. Korean Journal of Communication \& Disorders, 16, 185 201.

Tompkins, C. A. (1990). Knowledge and strategies for processing lexical metaphor after right or left hemisphere brain damage. Journal of Speech and Hearing Research, 33, 307-316.

Tompkins, C. A., Boada, R., \& McGarry, K. (1992). The access and processing of familiar idioms by brain-damaged and normally aging adults. Journal of Speech, Language, and Hearing Research, 35, 626-637.

Van Lancker, D. R., \& Kempler, D. (1987). Comprehension of familiar phrases by left-but not by right-hemisphere damaged patients. Brain and Language, 32, 265-277.

Wager, T. D., \& Smith, E. E. (2003). Neuroimaging studies of working memory: a meta-analysis. Cognitive, Affective and Behavioral Neuroscience, 3, 255-274.

Winner, E., \& Gardner, H. (1977). The comprehension of metaphor in braindamaged patients. Brain, 100, 717-729.

Yoo, N. (2014). The relationship between understanding of metaphor and working memory capacities of 5, 6 aged preschool children (Master's thesis). Dongshin University, Naju, Korea. 
Appendix 1. 참가자 상세 정보

\begin{tabular}{lccclc}
\hline 참가자 & 성별 & 연령 & $\begin{array}{c}\text { 교육 } \\
\text { 연수 }\end{array}$ & \multicolumn{1}{c}{ 병소 } & $\begin{array}{c}\text { 발병 후 } \\
\text { 기간(개월) }\end{array}$ \\
\hline RHD1 & 여 & 62 & 9 & Rt. BG, ICH & 11 \\
RHD2 & 여 & 65 & 9 & Rt. thalamic ICH & 12 \\
RHD3 & 여 & 56 & 14 & Rt. MCA Infarction & 6 \\
RHD4 & 남 & 52 & 16 & Rt. F-T lobes ICH & 27 \\
RHD5 & 남 & 49 & 16 & Rt. frontal lobe ICH & 10 \\
RHD6 & 여 & 62 & 12 & Rt. MCA Infarction & 18 \\
RHD7 & 여 & 60 & 12 & Rt. frontal lobe ICH & 10 \\
RHD8 & 여 & 67 & 12 & Rt. BG Infarction & 23 \\
RHD9 & 남 & 59 & 16 & Rt. frontal lobe ICH & 19 \\
RHD10 & 여 & 59 & 12 & Rt. BG, ICH & 8 \\
RHD11 & 남 & 61 & 12 & Rt. BG, ICH & 16 \\
RHD12 & 남 & 58 & 12 & Rt. OCcipital lobe ICH & 9 \\
NC1 & 남 & 60 & 16 & & \\
NC2 & 여 & 54 & 12 & \\
NC3 & 여 & 61 & 9 & \\
NC4 & 남 & 58 & 12 & \\
NC5 & 여 & 56 & 12 & \\
NC6 & 여 & 61 & 12 & \\
NC7 & 여 & 57 & 12 & \\
NC8 & 남 & 46 & 16 & \\
NC9 & 여 & 63 & 9 & \\
NC10 & 남 & 64 & 12 & \\
NC11 & 여 & 65 & 16 & & \\
NC12 & 남 & 60 & 12 & & \\
\hline & & \\
\end{tabular}

$\mathrm{RHD}=$ 우반구 손상 환자 집단; $\mathrm{NC}=$ 일반 성인 집단.
Appendix 2. 은유이해 과제 예시

\begin{tabular}{l} 
관습적 은유 \\
\hline 취업은 전쟁이다. \\
(1) 취업은 경쟁이 심하다. (적절한 해석) \\
(2) 취업은 무력을 행사한다. (사전적 의미의 해석) \\
(3) 취업은 대기업이 좋다. (관련 없는 해석) \\
짝사랑은 해바라기다. \\
(1) 짝사랑은 한 사람만을 바라본다. (적절한 해석) \\
(2) 짝사랑은 꽃의 한 종류이다. (사전적 의미의 해석) \\
(3) 짝사랑은 가슴이 아프다. (관련 없는 해석) \\
술은 독약이다. \\
(1) 술은 건강에 해롭다. (적절한 해석) \\
(2) 술은 마시면 죽는다. (사전적 의미의 해석) \\
(3) 술은 섞어 먹어야 맛있다. (관련 없는 해석) \\
\hline$\quad$ 새로운 은유 \\
\hline \\
영화는 비타민이다. \\
(1) 영화는 나를 즐겁게 한다. (적절한 해석) \\
(2) 영화는 인간에게 필수적인 물질이다. (사전적 의미의 해석) \\
(3) 영화는 장르가 매우 다양하다. (관련 없는 해석) \\
도박은 거머리이다. \\
(1) 도박은 끊기 어렵다. (적절한 해석) \\
(2) 도박은 피를 빨아 먹는다. (사전적 의미의 해석) \\
(3) 도박은 불법적으로 행해진다. (관련 없는 해석) \\
소문은 풍선이다. \\
(1) 소문은 점점 커진다. (적절한 해석) \\
(2) 소문은 하늘 높이 떠오른다. (사전적 의미의 해석) \\
(3) 소문은 몰래 전해진다. (관련 없는 해석) \\
\hline
\end{tabular}




\section{국문초록}

\section{우반구 손상 환자의 은유이해 특성 및 작업기억과의 관계 신효동' · 최소영 \\ '단국대학교 대학원 언어병리학과, ${ }^{2}$ 단국대학교 특수교육대학원}

배경 및 목적: 본 연구는 우반구 손상 환자들이 어려움을 보이는 화용 기능 중 은유이해 특성을 살펴보고, 작업기억과의 관련성을 확 인하고자 하였다. 방법: 본 연구의 참가자는 실어증이 동반되지 않은 우반구 손상 환자 12 명, 일반 성인 12 명이었다. 은유이해 과제는 친 숙도를 기준으로 관습적 은유와 새로운 은유로 구분하였으며 각 15 문항으로 구성하였다. 작업기억은 숫자 폭 과제와 단어 폭 과제를 각각 바로 따라말하기와 거꾸로 따라말하기 방식으로 측정하였다. 결과: 우반구 손상 환자 집단은 일반 성인 집단에 비해 은유이해 과 제 전반에서 수행의 어려움을 보였으나, 두 집단 모두 관습적 은유 조건을 새로운 은유 조건보다 쉽게 이해하는 것으로 나타났다. 또한 우반구 손상 환자 집단은 일반 성인 집단에 비해 모든 유형의 작업기억 과제에서 낮은 수행을 보였다. 상관 분석 결과에서는 두 집단의 양상이 다소 상이하였는데, 일반 성인 집단은 관습적 은유 유형과 단어 폭 과제 간에 유의한 상관을 보인 반면, 우반구 손상 환자 집단 은 관습적 은유와 새로운 은유 두 조건 각각에서 모든 작업기억 과제들과 정적 상관을 나타냈다. 논의 및 결론: 본 연구의 결과를 토대 로 우반구 손상 환자들이 겪는 은유이해의 어려움이 한정된 작업기억능력과 관련되어 있을 가능성을 논의하였다.

핵심어: 우반구 손상, 은유이해, 작업기억

이 논문은 제 1 저자의 석사학위 논문을 요약한 것임.

\section{참고문헌}

강연욱, 나덕렬, 한승혜(1997). 치매환자들을 대상으로 한 K-MMSE의 타당도연구. 대한신경과학회지, 15, 300-308. 고선희, 최경순, 황민아(2009). 읽기 폭 과제로 측정한 정상아동의 작업기억 발달. 언어청각장애연구, 14, 303-312.

김민영(2008). 우반구 뇌손상 환자의 속담이해능력: 속담의 친숙성과 문맥의 제시여부를 중심으로. 이화여자대학교 대학원 석사학위논문. 김은정, 최예린(2009). 우뇌손상 환자의 은유이해: 단어연상과 언어유추를 중심으로. 언어청각장애연구, 14, 70-81.

김향희, 나덕렬(2001). 파라다이스.한국판-웨스턴실어증검사. 서울: 파라다이스 복지재단.

박원경, 김광수(2012). 우측 대뇌 손상 환자의 작업기억 저하. 대한임상노인의학회지, 13, 186-193.

성지은(2010). 실어증 환자의 단기기억 및 작업기억용량과 실어증 중증도 및 문장처리와의 상관. 언어청각장애연구, 15, 285-297.

성지은(2011). 말언어장애군의 단기기억 및 작업기억 용량 측정을 위한 지시하기 과제 개발 예비 연구: 재검사 신뢰도 및 타당도. 언어청각장애연구,

16, 185-201.

오경민, 구세영(2008). 4, 5세 정상발달아동과 언어발달장애 아동의 억제조절 및 작업기억과 언어능력과의 관계. 언어청각장애연구, 13, 263-281.

유나(2014). 취학 전 아동들의 은유이해와작업기억 능력간의 관계. 동신대학교 대학원 석사학위논문.

이성희, 임종아, 황민아(2009). 우반구 뇌손상 성인의 은유이해: 과제제시조건의 미치는 영향 언어청각장애연구, 14, 484-494.

이소은, 조미라, 이윤경(2010). 초등학교 저학년 아동의 단락듣기 이해와작업기억 능력 간의 관계. 언어청각장애연구, 15, 56-65.

이종민, 김영욱(2003). 수화사용 청각장애인의 작업기억특성. 언어청각장애연구, 8, 209-227.

정승은(2008). 뇌손상 환자의 관용구 이해능력. 이화여자대학교 대학원 석사학위논문.

정우경(2003). 은유이해의 초기처리과정: 구조사상이론 대 범주포함이론. 이화여자대학교 대학원 석사학위논문.

홍영주, 임동선(2014). 학령기 단순언어장애아동의 작업기억과 은유 이해능력 간의 관계: 언어성 및 비언어성 과제를 중심으로. 언어청각장애연구,

19, 191-198.

황순택, 김지혜, 박광배, 최진영, 홍상황(2012). K-WAIS-IV 한국판 웩슬러 성인용 지능검사4판. 대구: 한국심리주식회사. 